\title{
Translation and validation of the Arabic version of the Boston carpal tunnel syndrome questionnaire
}

\author{
Mohammed H. Alanazy, MD, Malak Alaboudi, MBBS, Arwa Almaari, MBBS, Ziad Alhumayyd, MBBS, Hana Albulaihe, MBBS, \\ Taim Muayqil, MBBS.
}

\begin{abstract}
الأهداف: قمنا بترجمة والتحقق من صحة النسخة العربية من النس

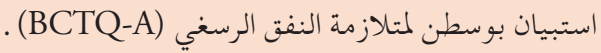

المنهجية : اشتملت الدراسة على مرضى متلازمة النفق الرسغي

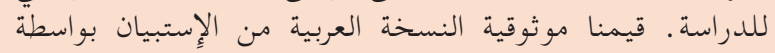

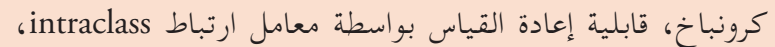

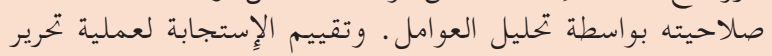
النفق الرسغي بواسطة Wilcoxon signed-rank test

النتائج : شارك 134 مريض، و كان متوسط مجموع النتائج لSSS

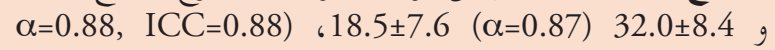

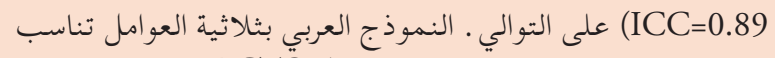

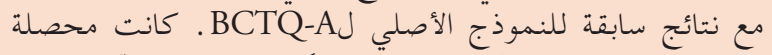

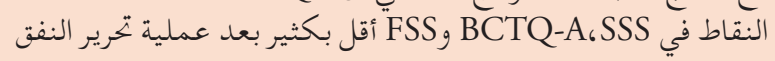

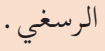

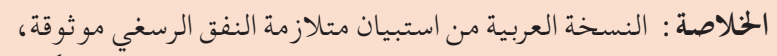

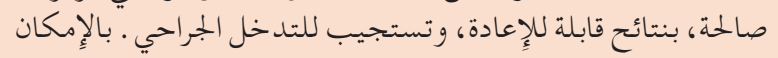

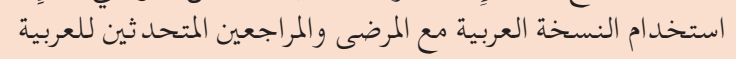

Objectives: To translate and validate the Arabic version of the Boston carpal tunnel questionnaire (BCTQ-A).

Methods: We recruited consecutive patients with carpal tunnel syndrome (CTS). Reliability was assessed with Cronbach $\alpha$, reproducibility with intraclass correlation coefficients, construct validity with factor analysis, and responsiveness post carpal tunnel release (CTR) with the Wilcoxon signed-rank test.

Results: In 134 patients, the mean total scores for the symptom severity scale (SSS) and functional status scale (FSS) were $32.0 \pm 8.4(\alpha=0.88, \mathrm{ICC}=0.88)$ and $18.5 \pm 7.6(\alpha=0.87, \mathrm{ICC}=0.89)$, respectively. As in the original Boston carpal tunnel questionnaire (BCTQ), a 3-factor model of the BCTQ-A best fitted the data.
The BCTQ-A, SSS, and FSS scores were significantly lower post-CTR.

Conclusions: The BCTQ-A is reliable, valid, reproducible, and responsive to interventions. The Arabic version can be now used with Arabic-speaking patients with CTS.

Neurosciences 2019; Vol. 24 (4): 296-301 doi: 10.17712/nsj.2019.4.20190014

From the Department of Internal Medicine, King Saud University Medical City and College of Medicine, King Saud University, Riyadh, Kingdom of Saudi Arabia.

Received 30th March 2019. Accepted 20th May 2019.

Address correspondence and reprint request to: Dr. Mohammed H. Alanazy, Division of Neurology, Department of Internal Medicine, King Saud University, Riyadh, Kingdom of Saudi Arabia.E-mail:dranazy@gmail.com

ORCID ID: https://orcid.org/0000-0001-5177-8283

O arpal tunnel syndrome (CTS) is a common entrapment neuropathy affecting the median nerve at the wrist. The diagnosis of CTS is made clinically and supported by the finding of median neuropathy at the wrist on electrodiagnostic studies (EDX). Atroshi et $\mathrm{al}^{1}$ reported a prevalence of clinically certain CTS of $3.8 \%$, and a prevalence of clinically and EDX confirmed CTS of $2.7 \%{ }^{1}$ Both carpal tunnel release (CTR) and conservative interventions are used for the treatment of CTS; the former may be more effective in relieving symptoms and improving hand function. ${ }^{2}$ A recent study has estimated a lifetime prevalence of CTR of $3.1 \%$. $^{3}$ The use of a validated outcome measure is imperative to monitor the response to CTS therapy.

The Boston carpal tunnel questionnaire (BCTQ) is a patient-reported outcome measure of proven reliability, validity, and responsiveness to surgical and non-surgical treatment. ${ }^{4-7}$ The BCTQ is composed of 2 scales, the symptom severity scale (SSS) and the functional status 
scale (FSS). The SSS consists of 11 items, incorporating 6 domains (pain, numbness, paresthesia, nocturnal symptoms, weakness, and overall functional status) scored on a 5-point scale ranging from 1 (never/none) to 5 (most severe). The FSS consists of 8 functional activities commonly affected by CTS scored on a 5 -point scale ranging from 1 (no difficulty) to 5 (cannot perform the activity at all). The BCTQ score reflects CTS severity in a typical 24-hour period within the last 2 weeks before completing the questionnaire. ${ }^{4,8}$ The BCTQ has been translated and validated in many languages, ${ }^{5,9-13}$ but not yet in Arabic. Validation of an Arabic version of the BCTQ would be useful to help physicians assess the impact of CTS from the patients' perspective and objectively assess post-intervention improvement. This study sought to translate and culturally adapt the BCTQ into Arabic and to assess its psychometric properties, including reliability, reproducibility, validity, and responsiveness to CTR.

Methods. Participants and data collection. This is a cross-sectional study. The study was conducted at King Saud University Medical City (KSUMC), Riyadh, Kingdom of Saudi Arabia. Patients were consecutively recruited from the Neurophysiology Clinic between January 2016 and May 2018. We enrolled patients 18 years of age or older who had clinical CTS confirmed by EDX. The diagnosis of CTS was confirmed by a neurologist, and was based on all of the following: (1) hand/wrist paresthesia (with or without pain), often awakening the patient from sleep, triggered by manual activities, and relieved by shaking the hands or placing them under running water, and (2) an EDX showing features of median neuropathy at the wrist as described previously. ${ }^{14}$

Patients were asked to complete the Arabic version of the BCTQ (BCTQ-A) after being interviewed by a neurologist who confirmed the diagnosis of clinical CTS. Illiterate patients were assisted by a family member in completing the questionnaire. After EDX was completed, only patients whose clinical CTS was confirmed by EDX were included in the study.

To test for reproducibility (test-retest reliability), 36 consecutive patients with CTS were asked to complete again the BCTQ-A after 1 week and return it by e-mail. To test for responsiveness, we subsequently contacted

Disclosure. Authors have no conflict of interests, and the work was not supported or funded by any drug company. those patients who had carpal tunnel release (CTR) 2 months after the procedure and asked them to complete an electronic version of the questionnaire.

The study was approved, as a part of a larger project (E-15-1581), by the Institutional Review Board of King Saud University. All participants signed an informed consent.

Translation and cultural adaptation. A multistep forward-backward translation method, according to the cross-cultural adaptation guidelines, ${ }^{15,16}$ was adapted to produce an Arabic version of the BCTQ. The translation process was conducted by a committee of 3 neurologists and 1 translator. Forward translation into Arabic was independently performed by 2 neurologists (both are bilingual, with Arabic as their first language). After reaching an agreement on the forward translation, the provisional Arabic version was independently backtranslated into English by a neurologist and a translator (both bilingual, with English as their first language). Any inconsistencies in translation were discussed by the committee members and resolved by consensus before producing the provisional Arabic version (BCTQ-A). For cognitive debriefing, 5 patients with CTS were asked to review the BCTQ-A and report any unclear items. Finally, production of the final version, BCTQ-A, was completed (Appendix).

Statistical analysis. Descriptive statistics was applied to demographic variables. For each individual, the SSS and FSS scores were obtained by summing the scores of the items on each scale. Reliability (internal consistency) of each scale of the BCTQ-A was assessed by Cronbach $\alpha$ coefficients. A Cronbach $\alpha>0.7$ was considered satisfactory. ${ }^{17}$

Reproducibility of the BCTQ-A was assessed on 36 stable patients with CTS with a 1-week test-retest, by computing the intraclass correlation coefficient (ICC) separately for each of the 2 scale scores. An ICC $>0.7$ was considered satisfactory. ${ }^{18} \mathrm{~A}$ Bland-Altman plot was used to assess the absolute agreement of the test-retest scores, and the $95 \%$ limits of agreement were calculated by using the formula $\mathrm{Md} \pm 1.96$ * $\mathrm{SDd}$, where $\mathrm{Md}$ is the mean difference between paired test-retest scores, and SDd is the standard deviation of these differences. The minimum detectable change (MDC) was defined as the minimal change in the scores of each scale required to differentiate a true change from a change due to variability in scoring or measurement error. The MDC was calculated using the formula $1.96^{*} \sqrt{ } 2^{*} S E M$, where SEM is the standard error of measurement. ${ }^{19}$ The SEM was calculated using the formula $S D b * \sqrt{ }(1-I C C)$, where $\mathrm{SDb}$ is the standard deviation of the baseline scores for each scale. 
(A)

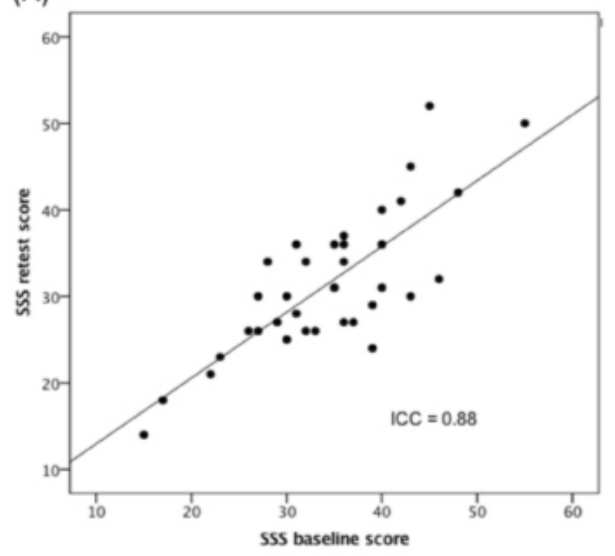

(B)

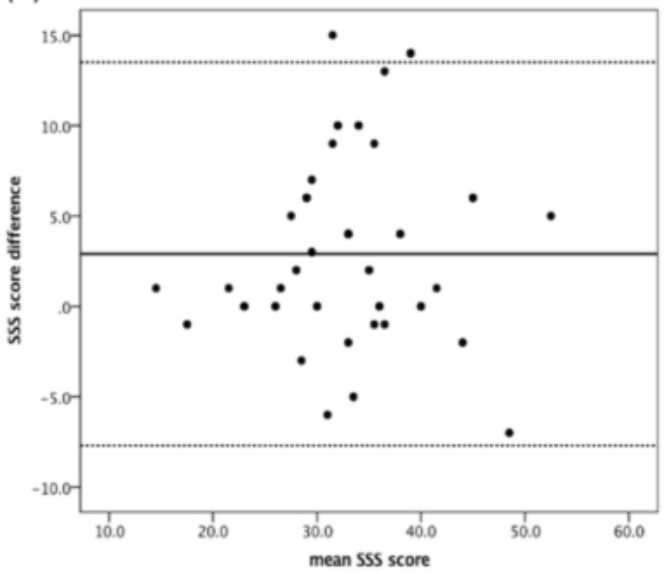

Figure 1 - Test-retest reliability of the symptom severity scale (SSS). A) Retest SSS score as a function of the baseline SSS score, B) Bland-Altman blot with $95 \%$ limits of agreement (dotted line).

(A)

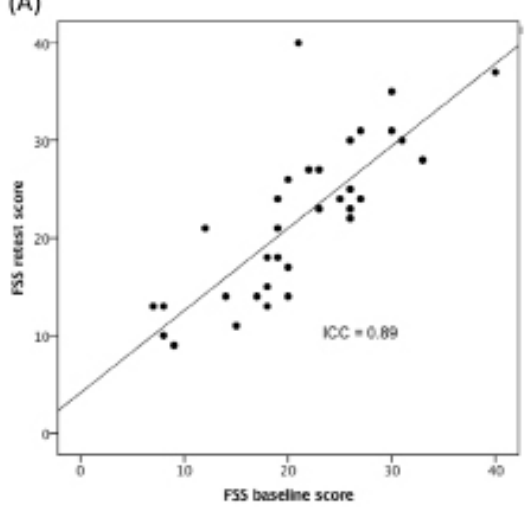

(B)

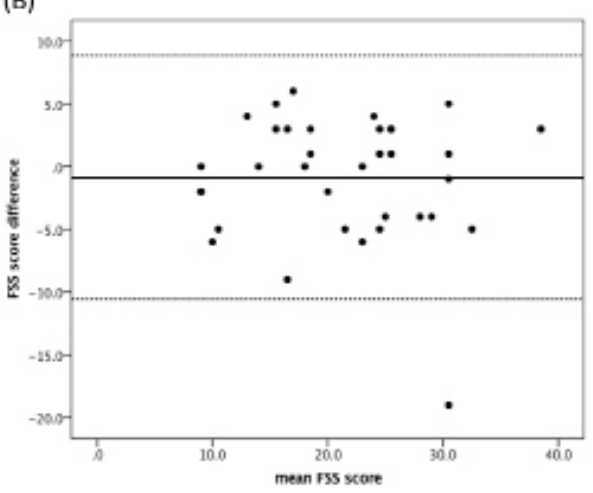

Figure 2 - Test-retest reliability of the functional status scale (FSS). A) Retest FSS score as a function of the baseline FSS score. B) Bland-Altman blot with $95 \%$ limits of agreement (dotted line).

Factor analysis was used to explore the latent variables (hypothetical constructs) of the BCTQ-A. Validity was assessed by comparing the latent variables and factor loadings of the BCTQ-A with those of the English version. The Cronbach $\alpha$ was calculated for each factor.

To assess for responsiveness, a Wilcoxon signed-rank test was performed to evaluate the differences in the total BCTQ-A, SSS, and FSS scores at baseline and at follow-up post CTR. The effect size (ES) was computed by dividing the test statistic by the square root of the number of observations (2 observations per patient, pre- and post-CTR). An ES of $>0.5$ was considered large, and an ES of 0.3 - 0.49 was considered moderate. Statistical analysis was performed using the statistical software SPSS version 23 (IBM, Armonk, N.Y, USA). A 2 -tailed $p<0.05$ was considered statistically significant.
Results. In total, 134 consecutive patients with clinically and EDX confirmed CTS (114 women, 20 men) participated. Of those, 109 (81.3\%) patients returned a completed questionnaire. The most frequently missing item was FSS item 1 (writing, $\mathrm{n}=17$ ), followed by FSS item 3 (holding a book while reading, $n=14$ ). The mean age of our cohort was $49.2 \pm 11.3$ years. CTS of the right or left hand was diagnosed in $41(30.6 \%)$ and $8(6 \%)$ patients, respectively, and of both hands in 85 $(63.4 \%)$ patients. No problems were encountered in the translation process, nor with the cognitive debriefing, as all the BCTQ items were readily translatable into Arabic language and consistent with the local culture.

Only data from completed questionnaires were included in the analysis. The mean SSS score

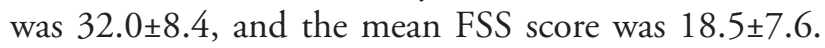


Table 1 - Factor loadings for the BCTQ-A scale items.

\begin{tabular}{llcc}
\hline Items & & \multicolumn{3}{c}{ Factors } \\
& & 1 & 2 \\
\hline SSS-1 & Hand/wrist pain at night - severity & & 0.642 \\
SSS-2 & Hand/wrist pain at night - wakening frequency & 0.565 & \\
SSS-3 & Hand/wrist pain - daytime & & 0.808 \\
SSS-4 & Hand/wrist pain - daytime, frequency & & 0.800 \\
SSS-5 & Hand/wrist pain - daytime, duration & & 0.525 \\
SSS-6 & Hand numbness - severity & & 0.397 \\
SSS-7 & Hand weakness - severity & 0.415 & \\
SSS-8 & Hand tingling - severity & & 0.647 \\
SSS-9 & Hand numbness/tingling - night, severity & & 0.920 \\
SSS-10 & Hand numbness/tingling - wakening, frequency & & 0.635 \\
SSS-11 & Grasping small objects & & \\
FSS-1 & Writing & 0.638 & \\
FSS-2 & Buttoning clothes & 0.698 & \\
FSS-3 & Holding a book while reading & 0.579 & \\
FSS-4 & Gripping a telephone handle & 0.785 & \\
FSS-5 & Opening jars & 0.596 & \\
FSS-6 & Household chores & 0.581 & \\
FSS-7 & Carrying of grocery bags & 0.664 & \\
FSS-8 & Bathing and dressing & 0.781 & \\
\hline Only factor loadings $>0.3$ were included in the table. ${ }^{*}$ FSS - functional status scale, SSS - symptom severity scale \\
\hline
\end{tabular}

Table 2 - Sensitivity to change of the total BCTQ-A, SSS, and FSS scales after carpal tunnel release surgery.

\begin{tabular}{|c|c|c|c|c|}
\hline \multirow[t]{2}{*}{ Scales } & Baseline & Follow-up & P-value* & ES \\
\hline & \multicolumn{2}{|c|}{$\mathrm{M} \pm \mathrm{SD}$} & & \\
\hline SSS $(n=36)$ & $33.1 \pm 9.4$ & $20.8 \pm 9.5$ & $<0.001$ & 0.55 \\
\hline FSS $(n=36)$ & $22.0 \pm 7.9$ & $17.8 \pm 9.1$ & 0.004 & 0.34 \\
\hline BCTQ-A $(n=36)$ & $55.1 \pm 16.1$ & $38.5 \pm 17.6$ & $<0.001$ & 0.51 \\
\hline
\end{tabular}

${ }^{*} p$-values were obtained using a Wilcoxon signed-rank test. BCTQ-A - Arabic version of the Boston carpal tunnel syndrome questionnaire, FSS - functional status scale, SSS - symptom severity scale, M - mean, SD - standard deviation, ES - effect size

The Cronbach $\alpha$ was 0.91 for the total BCTQ-A score, 0.88 for the SSS and 0.87 for the FSS. The ICCs for the SSS and FSS were 0.88 ( $95 \%$ confidence interval [CI] $0.77-0.94)$ and 0.89 (95\% confidence interval [CI] 0.79-0.95), respectively (Figures $1 \mathrm{~A}$ and $2 \mathrm{~A}$ ). The Bland-Altman plot showed good agreement between the 2 measurements for each scale, with no proportional bias. The Md for the SSS was 2.88 (95\% CI: -7.69 to 13.48), (Figure 1B). The Md for the FSS was -0.86 (95\% CI: -10.56 to 8.84 ), (Figure 2B). The SEM for the SSS and FSS were 2.9 and 2.6, respectively. The MDC for the SSS and FSS were 4.7 and 4.5, respectively, indicating that a score difference $\geq 5.0$ on either scale represents a true change.

Factor analysis of the combined 19 items from both scales was conducted. Principal axis factoring was used as an extraction method, followed by determination of factor loading using an oblique rotation method.
The Kaiser-Meyer-Olkin (KMO) measure was 0.85, suggesting sampling adequacy for each item, and that our data were suitable for factor analysis.

There was a discrepancy in the retention rules regarding the number of factors that could be extracted; using the criterion of eigenvalue (amount of variance in the total sample accounted for by a factor) greater than 1.0 indicated 4 factors, but parallel analysis indicated 2 factors. However, after examining the scree plot, and to validate our data in comparison to previous studies, ${ }^{20,21}$ we decided to extract three factors. The first factor of the BCTQ-A had an eigenvalue of 7.29, and explained $38.4 \%$ of the total variance of the BCTQ-A scores. The second and third factors had eigenvalues of 2.20 and 1.33 and explained $11.6 \%$ and $7.0 \%$ of the total variance of the scores, respectively. Thus, the 3 factors together explained $56.9 \%$ of the cumulative variance of the BCTQ-A scores. To analyze factor loadings, and 
due to the presence of correlation between the 3 factors (range 0.46-0.59), the "promax" oblique rotation method was employed. Using a cutoff of 0.3 to define significant loading, ${ }^{22}$ all the items of the FSS, and items 7 (hand weakness) and 11 (difficulty grasping small objects) of the SSS had significant loadings on factor 1 (functional status factor, Table 1). The SSS items 1 , $2,6,8,9$, and 10 had significant loadings on factor 2 (sensory symptoms factor). The SSS items 3, 4, and 5 had significant loadings on factor 3 (pain factor). No cross-loading or unloading were observed. The Cronbach $\alpha$ coefficients for factors 1,2 , and 3 were $0.89,0.85$, and 0.78 , respectively.

The responsiveness of the BCTQ-A, SSS, FSS was assessed in 36 patients at 2 months post-CTR. The total BCTQ-A, SSS, and FSS scores significantly decreased (indicating an improvement) post-CTR, with an average change of $16.6,12.3$, and 4.2 points, respectively (Table 2).

Discussion. This study described the successful translation and validation of the BCTQ into Arabic. No difficulties were encountered during the translation and cross-cultural adaptation, supporting the conceptual equivalence of the original and Arabic (BCTQ-A) versions. The BCTQ-A demonstrated excellent reliability, reproducibility, and validity, and is sensitive to changes, as shown by its responsiveness to CTR.

The internal consistency of the SSS and FSS of the Arabic version is similar to that of the original English version of the BCTQ. It is also similar to the internal consistency reported by other validation studies of the BCTQ. ${ }^{5,9,12,13}$ We decided to maintain a one-week interval to assess test-retest reliability; such interval would be long enough to allow patients to forget their initial responses but not long enough to allow for a true change in their CTS status. When calculating the scores for each scale on an individual level, we decided to use the sum of the scores rather than the mean score of all items, which was used in the original study. It is more practical for a busy clinician monitoring the response during a follow-up visit to add-up item scores than to calculate the mean. As we have demonstrated, a change of $\geq 5.0$ points on either scale represents a true change. Reproducibility of the BCTQ-A is confirmed by a satisfactory ICC for each scale, and is further supported by the good agreement of the successive measurements on the Bland-Altman plot. The ICCs for the SSS and FSS in this study are comparable to those measured in previous studies. ${ }^{9-13}$

Contrary to other studies, ${ }^{5,10-13}$ we did not use the correlation between the BCTQ-A and other quality- of-life outcome measures, but we chose exploratory factor analysis to test the hypothetical constructs of the BCTQ-A. The 3-factor structure (function, sensory symptoms, and pain) in our study provides the best account for the data, and explains $56.9 \%$ of the total variance. Factor loadings for all the 19 BCTQ-A items are satisfactory (Table 1). Moreover, the BCTQ-A does not have any complex items with cross-loading of > 0.3 . It is unclear why SSS item 6 has the lowest factor loading (0.397) of all the 19 items in our study. A previous study also showed low factor loadings for this item, and attributed it to the lack of specification of the exact time when numbness occurs, ${ }^{23}$ whereas its factor loadings in other studies were higher (ranged from 0.508 to 0.754 ) than in our study..$^{20,21}$ Nonetheless, all the BCTQ-A items in our study loaded on the correct factors, identical to those reported by Atroshi et al., ${ }^{20}$ and very similar to those reported by Ortiz-Corredor et al., ${ }^{21}$ the only exception being item 1 of the SSS that loaded on factor 3 in the latter study. In addition, the high Cronbach $\alpha$ coefficients of each of the three factors indicate homogeneity of their items. These findings indicate that factor analysis of the BCTQ-A produced the correct factor structure, and provided psychometric evidence for its validity. Therefore, until confirmatory factor analysis is conducted on a different cohort, we suggest retaining all the 19 items based on their clinical relevance and contribution to the factors.

The responsiveness of the Arabic version was supported by the ability of the BCTQ-A and its subscales to detect improvements post-CTR, with a significant $p$-value and an acceptable ES. Notwithstanding the differences in the methodology used to calculate the ES between our study and the original BCTQ, ${ }^{4}$ both studies showed a lower responsiveness of the FSS compared with the SSS. This has also been shown in other BCTQ validation studies. ${ }^{5,9,10,12}$ A time-lag in the post-CTR improvements in functional activities with respect to the improvements in symptoms severity is a possible explanation. However, the FSS is mostly a generic scale, and the activities included are affected by many musculoskeletal conditions of the upper extremities. An association between CTS and musculoskeletal injuries (rotator cuff syndrome and epicondylitis) has been reported, ${ }^{24-26}$ but was not examined in our study. Therefore, we cannot exclude a role of such conditions in hampering a more robust responsiveness of the FSS.

This study has a few limitations. Our sample size was relatively small for factor analysis when using only completed surveys. However, it met the minimum requirements (more than 5 participants per item, and more than 100 participants in total), ${ }^{22}$ and the values 
of factor loadings and KMO indicated the adequacy of the sample. The most frequently missed item in the BCTQ-A was FSS item 1, which concerns writing, followed by FSS item 3, which concerns the ability to hold a book while reading. Possible explanations for missing data could be that these activities were infrequently performed by patients who returned incomplete surveys, or illiteracy. Because there is no recommended methodology for handling missing data in the original BCTQ, the statistical analysis was only performed on complete questionnaires.

In conclusion, we have translated and culturally adapted the Arabic version of the BCTQ, and demonstrated its rigorous psychometric properties including reliability, reproducibility, validity, and responsiveness to CTR. The Arabic version can be now used for clinical and research purposes in Arab patients with CTS.

\section{References}

1. Atroshi I, Gummesson C, Johnsson R, Ornstein E, Ranstam J, Rosén I. Prevalence of carpal tunnel syndrome in a general population. JAMA 1999; 282: 153-158.

2. Shi Q, MacDermid JC. Is surgical intervention more effective than non-surgical treatment for carpal tunnel syndrome? A systematic review. J Orthop Surg Res 2011; 6: 17.

3. Pourmemari MH, Heliövaara M, Viikari-Juntura E, Shiri R. Carpal tunnel release: Lifetime prevalence, annual incidence, and risk factors. Muscle Nerve 2018; 58: 497-502.

4. Levine DW, Simmons BP, Koris MJ, Daltroy LH, Hohl GG, Fossel AH, et al. A self-administered questionnaire for the assessment of severity of symptoms and functional status in carpal tunnel syndrome. J Bone Joint Surg Am 1993; 75: 1585-1592.

5. Atroshi I, Johnsson R, Sprinchorn A. Self-administered outcome instrument in carpal tunnel syndrome. Reliability, validity and responsiveness evaluated in 102 patients. Acta Orthop Scand 1998; 69: 82-88.

6. Nuckols TK, Conlon C, Robbins M, Dworsky M, Lai J, Roth $\mathrm{CP}$, et al. Quality of care and patient-reported outcomes in carpal tunnel syndrome: A prospective observational study. Muscle Nerve 2018; 57: 896-904.

7. Chesterton LS, Blagojevic-Bucknall M, Burton C, Dziedzic KS, Davenport G, Jowett SM, et al. The clinical and costeffectiveness of corticosteroid injection versus night splints for carpal tunnel syndrome (INSTINCTS trial): an open-label, parallel group, randomised controlled trial. Lancet 2018; 392: 1423-1433.

8. Bessette L, Sangha O, Kuntz KM, Keller RB, Lew RA, Fossel $\mathrm{AH}$, et al. Comparative responsiveness of generic versus diseasespecific and weighted versus unweighted health status measures in carpal tunnel syndrome. Med Care 1998; 36: 491-502.

9. Imaeda T, Uchiyama S, Toh S, Wada T, Okinaga S, Sawaizumi $\mathrm{T}$, et al. Validation of the Japanese Society for Surgery of the Hand version of the Carpal Tunnel Syndrome Instrument. $J$ Orthop Sci 2007; 12: 14-21.

10. Lue YJ, Lu YM, Lin GT, Liu YF. Validation of the Chinese version of the Boston Carpal Tunnel Questionnaire. J Occup Rehabil 2014; 24: 139-145.
11. Park DJ, Kang JH, Lee JW, Lee KE, Wen L, Kim TJ, et al. Cross-cultural adaptation of the Korean version of the Boston carpal tunnel questionnaire: its clinical evaluation in patients with carpal tunnel syndrome following local corticosteroid injection. J Korean Med Sci 2013; 28: 1095-1099.

12. Kim JK, Lim HM. The Korean version of the Carpal Tunnel Questionnaire. Cross cultural adaptation, reliability, validity and responsiveness. J Hand Surg Eur Vol 2015; 40: 200-205.

13. Bougea A, Zambelis T, Voskou P, Katsika PZ, Tzavara C, Kokotis P, et al. Reliability and Validation of the Greek Version of the Boston Carpal Tunnel Questionnaire. Hand (N Y) 2018; 13: 593-599.

14. Alanazy MH. Clinical and electrophysiological evaluation of carpal tunnel syndrome: approach and pitfalls. Neurosciences (Riyadh) 2017; 22: 169-180.

15. Guillemin F, Bombardier C, Beaton D. Cross-cultural adaptation of health-related quality of life measures: literature review and proposed guidelines. J Clin Epidemiol 1993; 46: 1417-1432.

16. Beaton DE, Bombardier C, Guillemin F, Ferraz MB. Guidelines for the process of cross-cultural adaptation of self-report measures. Spine (Phila Pa 1976) 2000; 25: 3186-3191.

17. Frost MH, Reeve BB, Liepa AM, Stauffer JW, Hays RD, Mayo/ FDA Patient-Reported Outcomes Consensus Meeting Group. What is sufficient evidence for the reliability and validity of patient-reported outcome measures? Value Health 2007; 10: S94-S105.

18. Terwee CB, Bot SDM, de Boer MR, van der Windt DAWM, Knol DL, Dekker J, et al. Quality criteria were proposed for measurement properties of health status questionnaires. J Clin Epidemiol 2007; 60 :34-42.

19. King MT. A point of minimal important difference (MID): a critique of terminology and methods. Expert Rev Pharmacoecon Outcomes Res 2011; 11: 171-184.

20. Atroshi I, Lyrén PE, Gummesson C. The 6-item CTS symptoms scale: a brief outcomes measure for carpal tunnel syndrome. Qual Life Res 2009; 18: 347-358.

21. Ortiz-Corredor F, Calambas N, Mendoza-Pulido C, Galeano J, Díaz-Ruíz J, Delgado O. Factor analysis of carpal tunnel syndrome questionnaire in relation to nerve conduction studies. Clin Neurophysiol 2011; 122: 2067-2070.

22. Floyd FJ, Widaman KF. Factor analysis in the development and refinement of clinical assessment instruments. Psychol Assess 1995; 7: 286-299.

23. Lue YJ, Wu YY, Liu YF, Lin GT, Lu YM. Confirmatory Factor Analysis of the Boston Carpal Tunnel Questionnaire. J Occup Rehabil 2015; 25: 717-724.

24. Titchener AG, Fakis A, Tambe AA, Smith C, Hubbard RB, Clark DI. Risk factors in lateral epicondylitis (tennis elbow): a case-control study. J Hand Surg Eur Vol 2013; 38: 159-164.

25. Titchener AG, White JJE, Hinchliffe SR, Tambe AA, Hubbard $\mathrm{RB}$, Clark DI. Comorbidities in rotator cuff disease: a casecontrol study. J Shoulder Elbow Surg 2014; 23: 1282-1288.

26. Cartwright MS, Yeboah S, Walker FO, Rosenbaum DA, Newman JC, Arcury TA, et al. Examining the association between musculoskeletal injuries and carpal tunnel syndrome in manual laborers. Muscle Nerve 2016; 54: 31-35. 
استبيان بوسطن لمتلازمة النفق الرسغي

ماهي شدة ألم اليد او الرسغ أثناء الليل؟

- لأأعاني من ألم اليد أو الرسغ خلال الليليل (1)

- ألم خفيقف (r)

- ألم متوسط (؟)

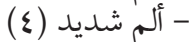

- ألم شديد جدا (0)

ما هو معدل استيقاظك من النوم بسبب آلام اليد أو الرسغ خلال آخر أسبوعين (مرة/يوم)؟

(أبدا (1)

(r)

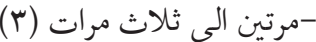

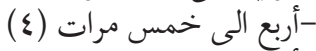

- أكثر من خمس مرات (0)

هل تعاني من ألم باليد أو الرسغ خلال النهار؟

- لا أعاني من ألم خلال النهار ألنار (1)

- أعاني من ألم خفيف خلال النهال النهار (r)

- أعاني من ألم متوسط خلال النهار النهار (r)

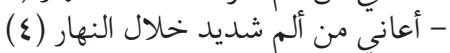

- أعاني من ألم شديد جدا خلال النهار (ه)

كم مرة تشعر بألم باليد أو الرسغ خلال النهار (مرة/يوم)؟

- أبدا (1)

- مرة أو مرتين باليوم (1)

-

-

- الألم مستمر (0) - (0)

اذا شعرت بالألم خلال النهار ، تقريبا كم تستغرق مدة الألم (بالدقائق)؟

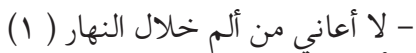

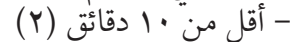

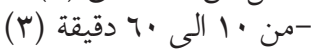

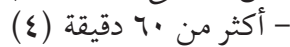

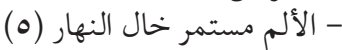

هل تلعاني من خدر (فقد في الاحساس) بيدك؟

- لا لا يوجذذ (1)

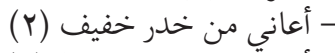

- أعاني من خدر متوسط (Y)

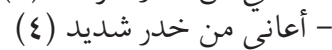

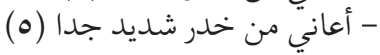

هل تعاني من ضعف باليد أو بالرسغ؟

- الا يوجذ ضعف (1)

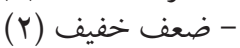

- ضعف متوسط (Y) (Y)

- ضعف شديد (؟) - 
استبيان بوسطن لمتلازمة النفق الرسني

هل تعاني من احساس بالتنميل في يدك؟

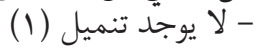

- تنميل خفيف (r) - (r)

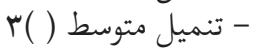

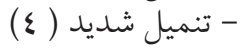

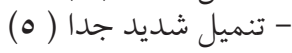

ما هي شدة الخدر (فقد الاحساس) أو التنميل في الليل؟

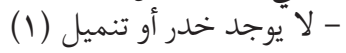

- خفيف (r) - الا توجد

- متوسط (Y) - (Y)

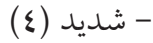

- شديد جدا (ه) - شد)

ما هو معدل استيقاظك من النوم ليلا بسبب خدر أو تنميل اليد خلال آخر أسبوعين؟

- أبدا (1)

- مرة واحدة (r)

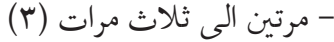

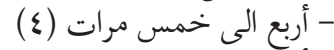

- أكثر من خمس مرات (ن)

هل تعاني من صعوبة بالإمساك أو استعمال الأشياء الصغيرة كالقلم أو المفتاح؟

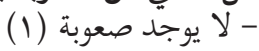

- صعوبة خفيفة (Y)

- صعوبة متوسطة (Y) - (ץ)

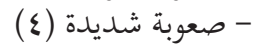

مستوى الحالة الوظيفية

خلال أي يوم من الأسبوعين الماضية ، هل سببت لك أعراض اليد أو الرسغ أي صعوبة في الأنشطة التالية؟ (يرجى وضع دائرة أمام الاختيار الأنسب)

\begin{tabular}{|c|c|c|c|c|c|}
\hline لا بسب أسعيع مارسة النشاط أب أبدا & صعوبة شديدة & صعوبة متوسطة & صعوبة خفيفة & لا يوجد صعوبة & الأنشطة \\
\hline 5 & 4 & 3 & 2 & 1 & الكتابة \\
\hline 5 & 4 & 3 & 2 & 1 & تزرير الملابس \\
\hline 5 & 4 & 3 & 2 & 1 & الكتاب ألتاء القراءة \\
\hline 5 & 4 & 3 & 2 & 1 & الهساك \\
\hline 5 & 4 & 3 & 2 & 1 & فتح العلب \\
\hline 5 & 4 & 3 & 2 & 1 & المنزلية \\
\hline 5 & 4 & 3 & 2 & 1 & حمل أكياس التسوق \\
\hline 5 & 4 & 3 & 2 & 1 & واللاستحمام \\
\hline
\end{tabular}

